\title{
Source Characterizations of Small Earthquakes
}

\author{
Ahmed Badawy ${ }^{1}$, Sh. Ali ${ }^{1}$ and A. El-Werr ${ }^{2}$ \\ ${ }^{1}$ Seismology Dept., National Research Institute of Astronomy and Geophysics, 11421-Helwan, Egypt \\ ${ }^{2}$ Geophysics Dept., Faculty of Sciences, Ain Shams University, Cairo, Egypt \\ Email: badawy@idsc.net.eg
}

\begin{abstract}
The source characterizations of five small felt earthquakes have been investigated using local seismograms of the Egyptian National Seismological Network (ENSN), Egypt. The studied earthquakes are located at three inland dislocations namely: Dahshour, southeast Beni-Suef and Cairo-Suez district. Throughout the analysis, Empirical Green's Function (EGF) deconvolution technique has been applied. The records of an appropriate aftershock are taken as the EGF and are used to deconvolve the mainshock seismograms, thus obtaining a Relative Source Time Function (RSTF) at each station. The deconvolution is performed using $P$ waves in frequency domain. From the time-domain analysis of the RSTF, the resulting source time functions indicate a complex rupture process for the strike-slip events (11 October, 1999 and 08 November, 2006)) and simple rupture process for the dip-slip events (28 December, 1999; 12 June 2001 and 17 December, 2001). The azimuthally dependencies of the RSTF pulse amplitudes and widths are used to estimate rupture velocity and rupture directivity. We found that the rupture directions are tending to propagate toward the north and NNW.
\end{abstract}

Keywords: Source characterization, small inland earthquakes, Empirical Green's Function, relative source time function, tectonic implications.

\section{Introduction}

It is important to understand how the rupture mode changes over a wide range of earthquake sizes in order to elucidate the generating mechanism of earthquakes. For small earthquakes the detailed analysis reveals that they occur with a variety of rupture modes and rupture velocities similar to large earthquakes (Frankel et al., 1986; Mori and Frankel, 1990; Li et al., 1995; Imanashi and Takeo, 2002). Moreover, it is difficult to rely on the distribution of aftershocks that clearly define the fault plane for small size earthquakes due to the lack of observations. For strike-slip events with source dimensions of a few meters to kilometers, the fault plane determination based on the rupture directivity criteria should be possible because the horizontal directivity effects due to finiteness of the source would be significant for the two nodal planes. Using a small earthquake as an Empirical Green's Function (EGF) to isolate the complicated path and site effects from observed seismograms, the relative source time function (RSTF) of a given earthquake can be extracted (Hartzell, 1978). The extracted RSTF contains information on the important parameters that characterize both the rupture process and source properties of the earthquake. Analysis of the RSTF reveals the rupture complexity and rupture directivity of small earthquakes (e.g., Frankel et al., 1986; Li and Thurber, 1988; Mori and Frankel, 1990; Abdel-Fattah and Badawy, 2002). The retrieved RSTF also demonstrated that the rupture directivity along with the focal mechanism of an earthquake could be used to determine the actual fault plane (Mori and Hartzell, 1990; Mori, 1993; Badawy and Abdel-Fattah, 2001).

Seismicity map of Egypt (Fig. 1) shows that the main activity occurred in northern part of the Egyptian territory. The relative motion of the Sinai subplate with respect to the Arabian plate (Gulf of Aqaba and Dead Sea) and to the African plate (Gulf of Suez) represents the main source of active tectonics and seismic activity. Moreover, it can be considered as a direct seismotectonic consequence of the Sinai subplate kinematics (Badawy, 1996; 1999; Badawy and Horváth, 1999a, b). Outside this relatively active zone, inland or intra-plate seismic active dislocations are also reported (Badawy, 2005a, b; Abo Elenean, 2007). These inland earthquake dislocations are important because they greatly expand 
the region of possible seismic hazard. Their role in tectonics is poorly understood, owing to their complexity, and therefore, it is of great importance to study source mechanisms and depths of the small to moderate size earthquakes. Badawy et al. (2013) have been defined three inland earthquake dislocations namely: Dahshour, southeast Beni-Suef and Cairo- Suez district. Earthquake activities tend to occur in clusters along the first dislocation (Dahshour) however relatively scattered along the second (southeast Beni-Suef) and the third (Cairo-Suez district) dislocations.

In the present study, the $P$-waveform data have been analyzed in detail to extract RSTF using EGF deconvolution approach and thus investigating the characteristics of the rupture process of five small felt inland earthquakes in northern Egypt since the operation of the modern digital Egyptian National Seismological Network (ENSN) in 1997. Two earthquakes (nos. 3 and 4 in Table 1) from the studied five events were located at Dahshour dislocation and other two events (nos.1 and 5 in Table 1) were located at southeast Beni-Suef, however, the fifth one (no. 2 in table 1) was located at Cairo-Suez district dislocation. Finally, we have discussed the obtained results in the seismotectonics context of northern Egypt.

Table 1. Source parameters of the studied five small felt inland earthquakes and their aftershocks (EGF's) in northern Egypt.

\begin{tabular}{ccccccccccc}
\hline No & Date & Time & Lat. & Long. & ML & Mw & $\begin{array}{c}\text { Mo } \\
(\mathbf{N m})\end{array}$ & $\begin{array}{c}\text { Slip } \\
(\mathbf{c m})\end{array}$ & $\begin{array}{c}\text { Stress } \\
(\mathbf{M P a})\end{array}$ & $\begin{array}{c}\text { Fault } \\
(\mathbf{K m})\end{array}$ \\
\hline 1 & 1999.10 .11 & $20: 39: 34.6$ & 28.68 & 31.52 & 5.0 & 4.4 & $5.04 \mathrm{E} 15$ & 9.1 & 49.1 & 1.5 \\
& 1999.10 .15 & $09: 04: 03.7$ & 28.74 & 31.53 & 3.2 & 2.7 & $1.14 \mathrm{E} 13$ & 0.2 & 13.6 & 0.5 \\
& & & & & & & & & & \\
2 & 1999.12 .28 & $12: 05: 11.1$ & 30.24 & 31.46 & 4.8 & 4.5 & $5.55 \mathrm{E} 15$ & 9.3 & 38.4 & 0.8 \\
& 1999.12 .28 & $16: 29: 08.5$ & 30.20 & 31.50 & 3.3 & 3.6 & $1.91 \mathrm{E} 14$ & 6.9 & 19.0 & 0.5 \\
& & & & & & & & & & \\
3 & 2001.06 .12 & $13: 43: 26.5$ & 29.64 & 31.14 & 4.4 & 4.2 & $3.18 \mathrm{E} 15$ & 6.1 & 39.4 & 0.7 \\
& 2001.06 .12 & $15: 50: 30.0$ & 29.66 & 31.13 & 3.3 & 3.1 & $2.02 \mathrm{E} 13$ & 0.4 & 18.7 & 0.3 \\
& & & & & & & & & & \\
4 & 2001.12 .17 & $04: 26: 32.5$ & 29.56 & 30.87 & 4.4 & 4.1 & $2.86 \mathrm{E} 15$ & 5.3 & 36.8 & 0.6 \\
& 2001.12 .17 & $08: 12: 25.2$ & 29.54 & 30.83 & 3.0 & 2.8 & $6.78 \mathrm{E} 12$ & 0.1 & 16.4 & 0.4 \\
& & & & & & & & & & \\
5 & 2006.11 .08 & $04: 32: 00.0$ & 28.57 & 31.55 & 4.1 & 3.5 & $1.76 \mathrm{E} 14$ & 1.8 & 23.8 & 0.5 \\
& 2006.11 .08 & $05: 34: 00.0$ & 28.58 & 31.62 & 2.5 & 2.4 & $4.91 \mathrm{E} 12$ & 0.1 & 12.1 & 0.3 \\
\hline
\end{tabular}

\section{Seismotectonics of Northern Egypt}

Egypt located at the northeastern part of Africa; is bounded to the north by the Mediterranean Sea and to the east by the Red Sea and Gulf of Aqaba. Geodynamically, Africa may be considered as a stable region except the East African Rift that branches in northern Ethiopia into Red Sea Rift and Gulf of Aden Rift. In northern Egypt, the Red Sea branches into Gulf of Suez and Gulf of Aqaba. As a matter of fact, Egypt is situated within the Alpine orogenic belt which represents a broad plate boundary zone between the colliding African and Eurasian plates. Therefore, in the territory of Egypt three major geologic trends are recognized, namely the Red Sea trend oriented NW-SE, the Gulf of Aqaba trend oriented NE-SW and the Mediterranean trend oriented E-W (Youssef, 1968). Faults and lineaments in these trends are shown on geologic maps and satellite images (Egyptian Geological Survey, 1981; General Petroleum Company, 1987; Remote Sensing Centre, 1990).

On the basis of earthquake distribution (Fig 1), Egypt can be divided into the two tectonic provinces: northern Egypt (north of $27^{\circ} \mathrm{N}$ ) and southern Egypt. The first province is more seismically active than the second province. The northern part of Egypt is tectonically unique. The east boundary is characterized by the divergence being accompanying the extension and north boundary of that is characterized by the convergence being accompanying the compression. The high level of seismic activity in northern Egypt is interpreted as a result of the interaction between the African, Arabian and Eurasian plates. Moreover, the main earthquake activity in this region can be considered as a direct 
seismotectonic consequence of the Sinai subplate kinematics (Badawy, 1996, 1998; Badawy and Horváth, 1999a, b). It was also demonstrated that these provinces differ in stress patterns too (Badawy, 2001a, b).

Despite the fact that the earthquake activity in northern Egypt is relatively moderate, the seismic risk is considerably high. This is due to the fact that most of earthquakes take place near over-populated cities and villages, coupled with the little awareness of knowledge and dealing with geo-hazard problems, in particular, earthquakes. Figure 2 depicts earthquake activity and source mechanisms of studied events in northern Egypt from 1997 to 2013. From figures 1 and 2 it is clear that northern Egypt has suffered not only from interplate earthquakes but also from inland seismic dislocations.

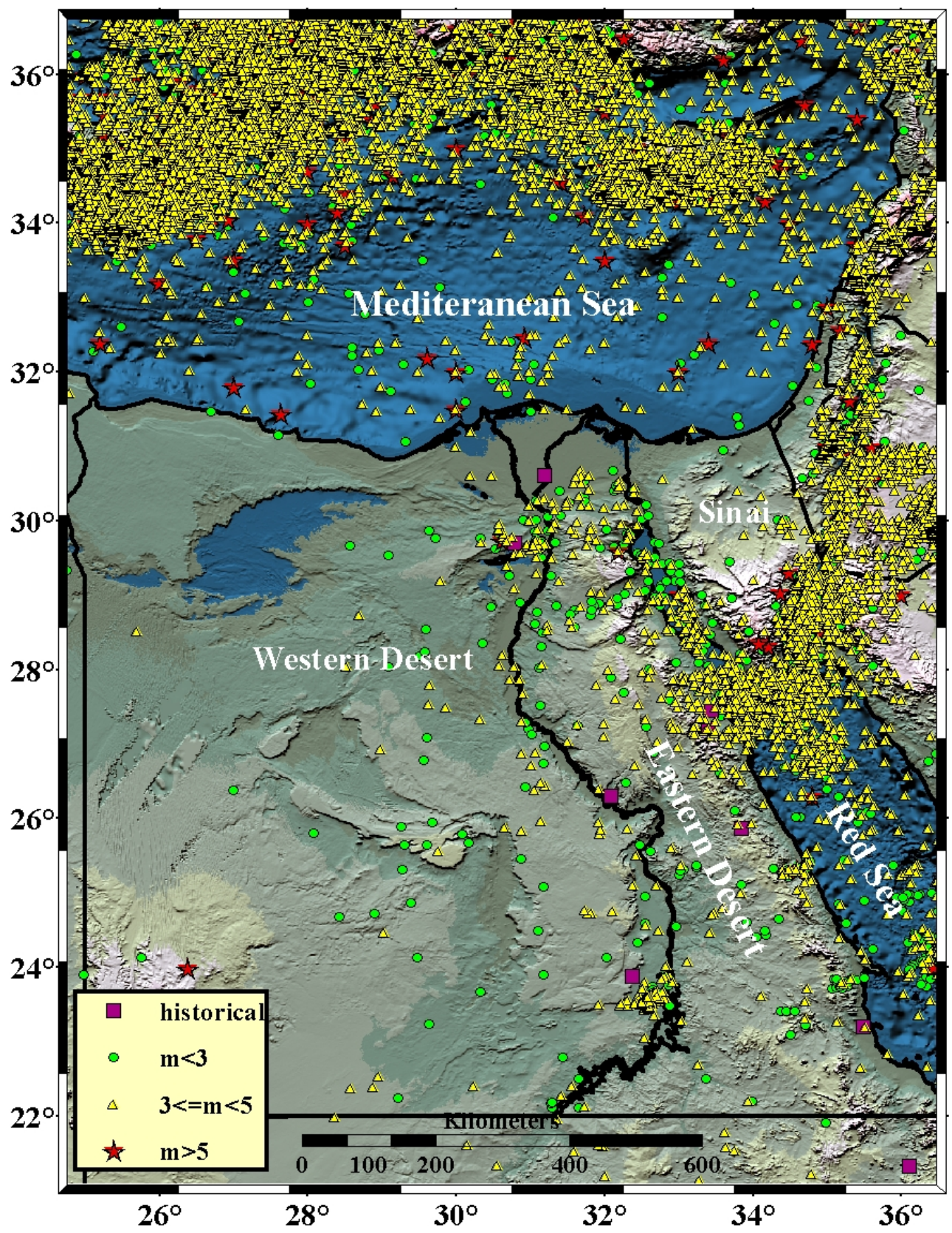

Figure 1. Seismicity map of Egypt ENSN data files from 1997 to 2009 


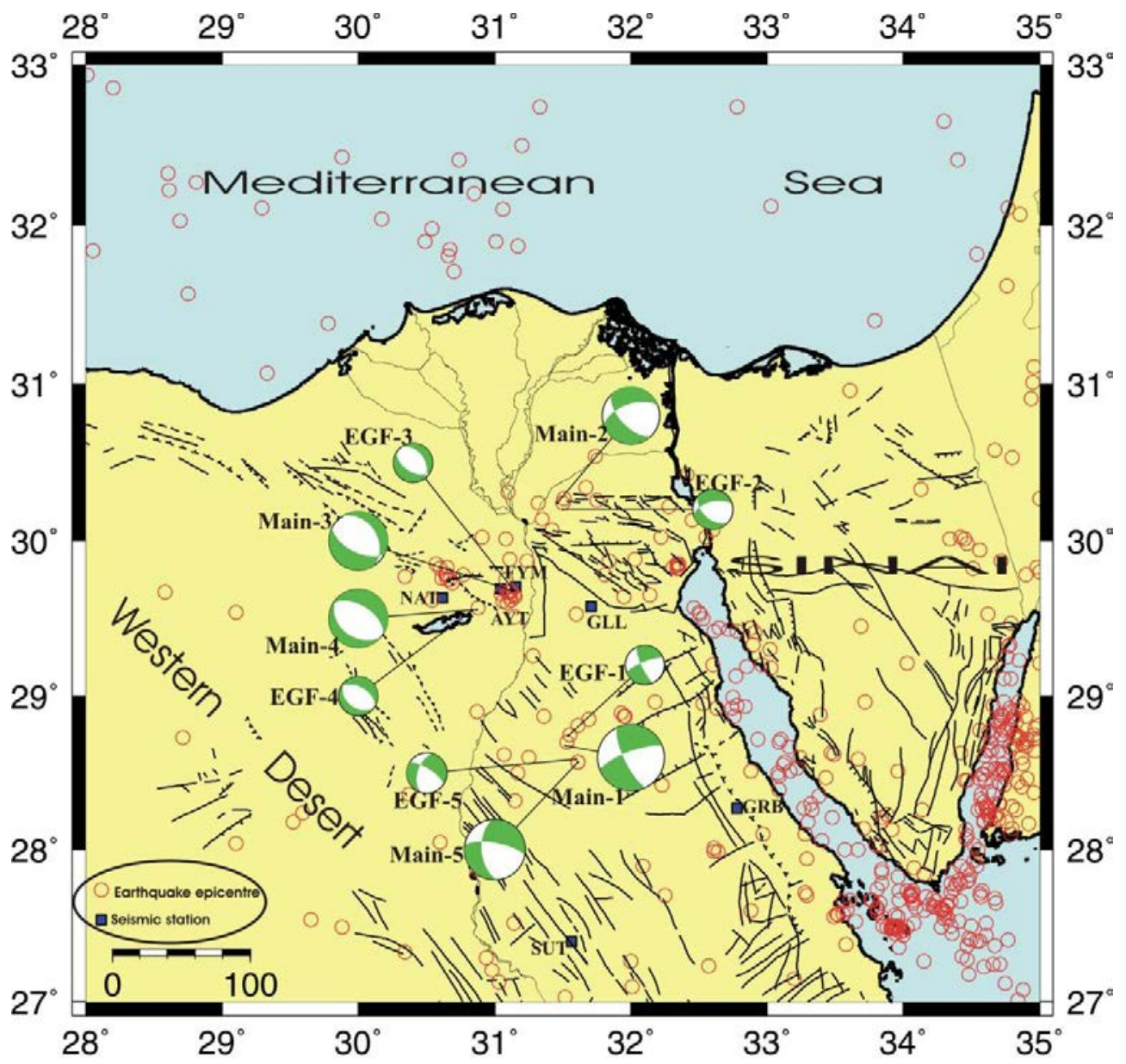

Figure 2. Epicentral distribution of recent earthquakes in northern Egypt from 1997 to 2013. Earthquake source mechanisms of main-shock and empirical green functions (EGF's) are shown. Surface faults are also illustrated.

Moreover, the general distribution of earthquake epicenters falls into three major trends. The first trend (Clysmic) extends from the Gulf of Suez through the cities of Cairo and Alexandria. The activity along this trend is mainly attributed to the Red Sea rifting and characterized by shallow earthquakes and microearthquakes (Kebeasy, 1990). The second trend (Pelusiac) extends from the eastern Mediterranean Sea to the southeast Cairo and Fayoum region. Along this trend, small to moderate historical and recent earthquakes have been observed. Along the Aqaba Levant trend (the third one), the seismic activity is highly related to the Gulf of Aqaba-Dead Sea fault system. The investigated events and many remarkable earthquakes (29 April 1974, 2 January 1987, 14 December 1987, 22 May 1992, 19 November 2001) took place along these trends. The first trend intersects the second one at Cairo city. Within this intersection, the moderate earthquake of 12 October $1992(M b=5.9)$ has occurred.

The local stress field gives the main factor, which is controlling the inland earthquake activity in addition to regional stress field that is related to plate's interactions. Therefore, temporal investigations of microearthquakes might help towards understanding the physical processes of earthquake generation and local stress field deviations. The present-day stress field, derived from several focal mechanisms and borehole breakouts (Badawy 2001a, b), shows a trans-tensional stress regime with a tension axis striking about N-S to NE-SW in northern Egypt. Three fault trends affect the studied area. The trend of most of the faults is E-W (Mediterranean); some faults have a NW (Red Sea - Gulf of Suez) trend and a few have a NE (Aqaba) trend. The stresses, which created the structure in this area, were tensional rather compressional (Shukri, 1953; Said, 1962). All these faults are of normal type and no thrusting is observed in the area (Said, 1962). 


\section{$3 \quad$ Data and Methodology}

The waveform data used in this study were recorded by the ENSN operated by the National Research Institute of Astronomy and Geophysics (NRIAG). ENSN comprises 68 remote sites transmitting data to the main centre at Helwan, Cairo via satellite communications. All instruments are either short period velocity sensors $(65 \%)$ or broadband seismograph stations (35\% with STS-1 seismometers) with a 24- bit digital recording system with sampling rate of 100 sample/s. The instrument response is flat, from 1.9 to $38 \mathrm{~Hz}$. The dynamic range is of about $124 \mathrm{~dB}$. For waveform analysis, we used only the $P$-wave part of velocity records. The analysis is based on the idea that the seismogram from a small co-located earthquake can be used as an EGF to extract the RSTF of a large earthquake. Figure (2) shows the locations and source mechanisms of the five investigated earthquake couples. The most advantage of using the waveform of the small earthquake as an EGF is that detailed knowledge of the earth structure, instrument response, attenuation and site effects is not required. The idea of the Empirical Green's Function (EGF) has been presented in the late 1960s by Aki, (1967) and later applied to seismic source analysis by Hartzell, (1978).

This approach had been subsequently used and developed by Mueller (1985), Fukuyama and Irikura (1986), Mori and Frankel (1990), Ammon et al. (1993), Velasco et al. (1994), Ihmle' (1996), Courboulex et al. (1996), Bertero et al. (1997), and Valle'e (2004). Once an appropriate EGF is selected for a given mainshock, the body-wave (typically, P-wave) seismograms are windowed manually to a length of 1-1.5 sec. The windows are adjusted depending on the propagation characteristics between source and receiver to ensure the signal is completely captured. Each window is referenced to the origin time and the epicenter of each event, so that the phase of the deconvolution is sensitive to these parameters. The mean of each seismogram is removed and a Hanning window is applied to taper the seismogram near the ends then Fourier transformed to frequency domain. For higher-resolution investigations, time-domain approaches based on linear-inverse theory may be more appropriate since they provide detailed information on the uncertainties of the resulting time functions and allow easy incorporation of a priori constraints (Hartzell and Heaton, 1985; Sipkin and Lerner-Lam, 1992 and Ammon, 1992).

Hence, the EGF events divided the amplitude spectrum of larger events and the phase spectrum of the EGF events was subtracted from that of the larger events. The resulting amplitude and phase spectra were then inverse-transformed to obtain the RSTF. After deconvolution, a sixth-order Butterworth low-path filter with a corner frequency of $30 \mathrm{HZ}$ was used to reduce the high frequency noise. This noise may be caused by the variation of background noises at the stations, the spatial separation between the larger and EGF events (Frankel et al., 1986 and Li and Thurber, 1988). The stability of the deconvolution is judged by inspection, and often, those deconvolutions first judged unstable are found to actually contain information on differences in the focal mechanisms of the EGF and mainshock.

The fundamental application of the EGF method is to retrieve the far-field source time function by deconvolving a small earthquake seismogram from that of a larger earthquake. When a small earthquake (aftershock or foreshock) can be interpreted as a point source, the observed seismogram of an event at any point $\boldsymbol{x}$ and $\boldsymbol{t}$ can be expressed as

$$
U_{L}(x, t)=u_{L}(t) * P(x, t) * R(t) * I(t)
$$

where $u_{L}(t)$ is the source time function, $P(x, t)$ represents the propagation effect, $R(t)$ represents the recording site effect, $I(t)$ is seismic instrument response, ${ }^{*}$ represents convolution and $L$ refers to a large event. For EGF event, Equation (1) can be written as

$$
U_{S}(x, t)=u_{S}(t) * P(x, t) * R(t) * I(t)
$$

When the source pulse of the EGF event is short enough, its source time function can be considered as a delta function. Therefore, we can write equation (2) as

$$
U_{S}(x, t)=\delta(t) * P(x, t) * R(t) * I(t)
$$

At the same seismic station, the effects of propagation path, recording site, and instrument response will remove throughout division equation (1) by equation (3)

$$
U_{L}(x, t)=u(t) * U_{S}(x, t)
$$

The processing of this equation can be performed in the vector form as 


$$
d=m \cdot G
$$

where $d$ is the vector representing the observed data for the master event, $m$ is the vector that represents the deconvolution pulses and $G$ is a $N \mathrm{x} M$ convolution matrix that represents the observed data for the EGF event. This equation can be solved deconvolution in the time domain by linear least squares. Figures 3, 4 and 5 represent three examples of mainshock, EGFs and relative source time functions at selected ENSN stations as well.

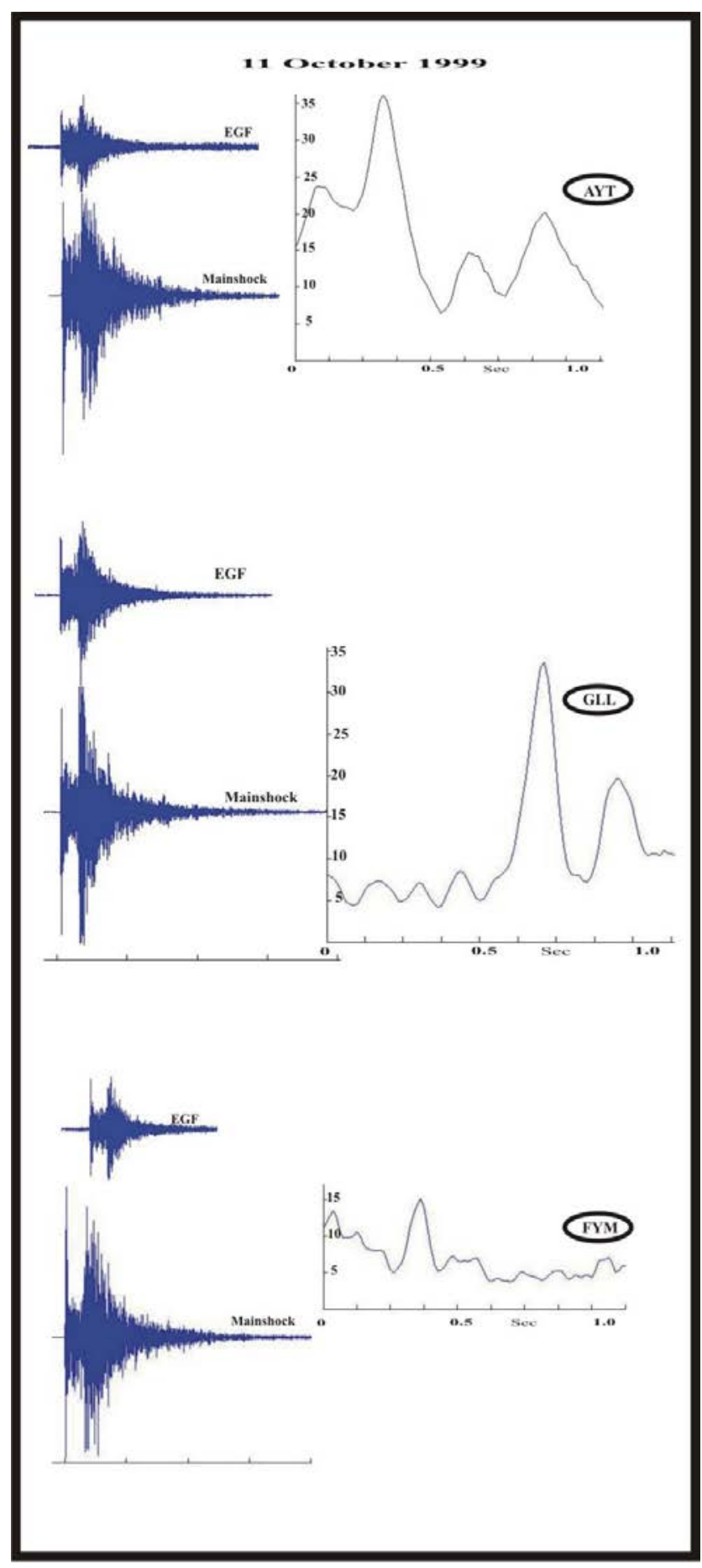

Figure 3. velocity seismogram of (3) me main-shock and EGF of the 11 October 1999 earthquake at selected ENSN stations. 


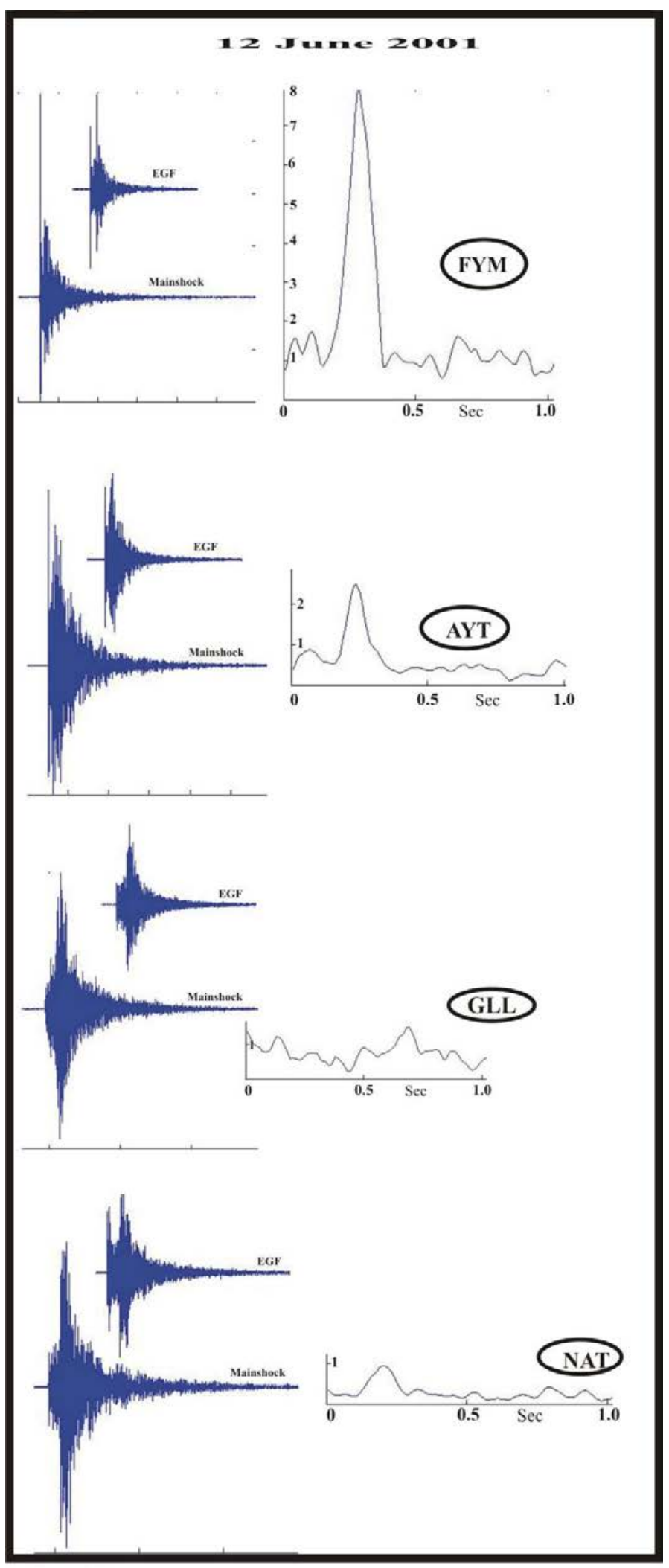

Figure (4)

Figure 4. velocity seismogram of the main-shock and EGF of the 12 June 2001 earthquake at selected ENSN stations. 


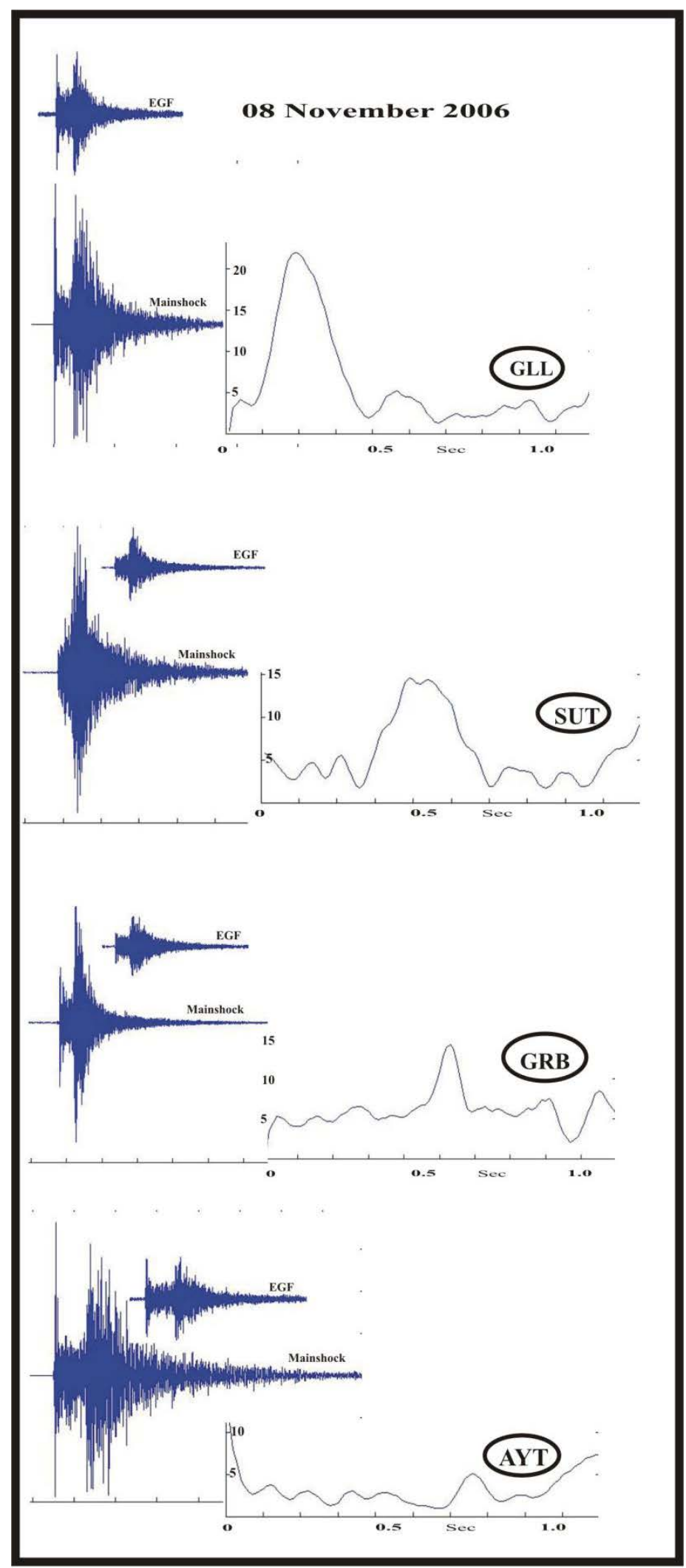

Figure (5)

Figure 5. velocity seismogram of the main-shock and EGF of the 08 November, 2006 earthquake at selected ENSN stations. 


\section{$4 \quad$ Relative Source Time Functions}

To obtain the RMRF of the mainshocks, we preformed the deconvolution as a linear least square estimation problem in the time domain with nonnegative by using NNLS Fortran subroutine that introduced by Lawson and Hanson (1974). Because the EGF deconvolution is an unstable operation, it is necessary to reduce the instabilities in the high frequency noise. Therefore, the deconvolved pulses are low-pass causal filtered at $30 \mathrm{~Hz}$ high cut frequency with a Butterworth filter. The noise instabilities may be caused by the variation of back ground noise at the stations, the spatial separation between the master and EGF event, and the non deltaness of the RSTF of the EGF event (Frankel et al., 1986; Li and Thurber, 1988, Li et al., 1995). Important information of the deconvolved pulses is contained in the peak amplitudes and pulse widths. Since these pluses are retrieved, factors such as the radiation pattern, geometrical spreading, free surface amplification and instrument gain are cancelled.

Thus the amplitude and pulse width of the deconvolved pluses for a given earthquake can be directly compared between stations to reveal the directivity of the source. The following five sections summarize the source characterizations of the studied small felt inland earthquakes.

\subsection{The Event No.1 (11 October, 1999)}

On Monday 11th October 1999, an earthquake of moment magnitude Mw 4.4 hit Northern Egypt. This event shook the greater Cairo region and northern part of the Nile valley and was felt in much of northern Egypt with epicentral intensity of V (EMS). It was followed by eight aftershocks with local magnitude ranging from 1.6 to 3.2. A detailed analysis of this sequence, cross-correlation analysis, fault plane solutions and source parameter estimations was performed by Badawy and Abdel- Fattah (2001). The focal mechanism solutions for the main-shock and the largest aftershock (Figure 2) are moderately controlled and indicate strike-slip faulting with a minor dip-slip normal component. The aftershock locations provide an independent determination of the rupture plane and help to verify that the rupture directivity can resolve the details of the rupture sufficiently to choose the fault plane. The nodal plane that has a NNW trend fits quite well the geometry derived from the aftershocks alignment.

The deconvolution pulses of this event at selected ENSN stations are shown in Figure 3 . The extracted RSTFs exhibit complex pulses with 3-4 sub-events imply a complex rupture process. The shape and amplitudes of RSTFs reflect a northward propagation of the rupture. Speculations of the preferred fault geometry based on rupture directivity combined with generalized isoseismal lines, focal mechanisms and aftershock distribution suggest that the rupture mainly propagated unilaterally toward NNW.

\subsection{The Event No.2 (28 December, 1999)}

On Tuesday 28th December, 1999 an earthquake sequence occurred in northern Egypt, about 25-km northeast of Cairo. The main-shock of Mw 4.5 was widely felt throughout the greater Cairo region and followed 12-minutes later by a Mw 3.9 aftershock and 4 hours later by a Mw 3.6 aftershock. This earthquake sequence yields an amount of good waveform data providing a unique opportunity to study the physical processes of small earthquake occurrences. However, the detailed characteristics of the seismically active faults in northern Egypt and the nature of stresses on them are not well known. Thus, an estimation of the source parameters of earthquakes might provide a better understanding of physical processes responsible for seismicity. Assuming a double-couple point source, the focal mechanism solutions of the main-shock and the largest aftershock show normal faulting with strike-slip component (Figure 2) with two nodal planes trending ENE and NW. Due to the facts that the two strikes agree with the general trends of the tectonic lines in northern Egypt (Youssef, 1968) and the depth of focus is as deep as $19 \mathrm{~km}$, we are not able to distinguish the fault plane on the basis of surface geology and aftershock distributions.

Although, the azimuthally coverage of the stations is distributed toward the south (Figure 2) the obtained RSTFs provide evidence the rupture directivity. This event is characterized by simple rupture with distinct peak. Estimated rupture directions were incorporated with P-wave focal mechanisms to identify the actual fault planes of this event. Therefore, the preferred fault plane is that strike of $137^{\circ}$, dip of $59^{\circ}$ and rake of $-39^{\circ}$. In this case, the slip component in strike direction indicates a left lateral 
motion along the NW fault. Moreover, the nodal oriented NW may be selected as preferred rupture plane because of its agreement with tectonic evolution model of the Sinai subplate and Gulf of Suez region (Badawy, 1996; Badawy and Horváth 1999a, b). The obtained results imply the reactivation of the Oligocene deep seated faults in the Gulf of Suez-Read Sea trend (NW-SE).

\subsection{The Event No. 3 (12 June, 2001)}

On Tuesday, $12^{\text {nd }}$ June 2001 a small earthquake with $\mathrm{M}_{\mathrm{w}} 4.2$ was jolted northern Egypt without any damages. It was located at Dahshour dislocation 35-km southwest Cairo, northern Egypt. It was widely felt from north delta in the north to Assuit city in the south. Very close to the epicentral area an explosion-like sound was heard at distance up to $20 \mathrm{~km}$. Within two hours later, it was followed by an aftershock of $\mathrm{M}_{\mathrm{w}}$ 3.1(Table 1). The source mechanisms of the mainshock and empirical green function show normal faulting mechanism with very minor strike-slip component (Figure 2). Based on previous studies and geological situation of the Dahshour dislocation the fault plane striking 328, with dip 37 and rake -74 may be the actual rupture plan.

The extracted RSTFs of this event at selected ENSN stations are shown in Figure 4. They reflect a simple rupture process with a distinct having the maximum amplitude in ENE-WSW direction. The largest amplitude is in FYM station that has an azimuth of $285^{\circ}$, the RSTF of FYM station is characterized by a narrow pulse width, where NAT station has the smallest amplitude and also narrow pulse width. SQR and GLL stations have moderate amplitude and the widest pulse width. This means that, the rupture propagates roughly towards FYM station.

\subsection{The Event No. 4 (17 December, 2001)}

In the early morning hours on Monday $17^{\text {th }}$ December 2001 at 04:26:32 (GMT) a small earthquake of $\mathrm{M}_{\mathrm{w}} 4.1$ was shook northern Egypt. The quake was felt as far as Cairo and its surroundings while no casualties were reported. It was located at Dahshour dislocation 35-km southwest Cairo, northern Egypt. The focal mechanism solutions of the mainshock and the aftershock show pure normal faulting mechanism with a preferred plan striking 302 with dip 53 and rake -93 to be the rupture direction.

The deconvolution pulses exhibit a simple rupture with one peak. The analysis of the shape and amplitude of the extracted RSTFs reflect a NNW-SSE direction for the rupture history of this event.

\subsection{The Event No. 5 (8 November, 2006)}

In the early morning hours on Wednesday November 08, 2006 at 04:32:10(GMT) a small earthquake of $\mathrm{M}_{\mathrm{L}} 4.1$ occurred at southeast Beni-Suef, approximately 160-km SEE of Cairo, northern Egypt. The quake was felt as far as Cairo and its surroundings while no casualties were reported. The instrumental epicenter was located at $28.57^{\circ} \mathrm{N}$ and $31.55^{\circ} \mathrm{E}$. Seismic moment was $1.76 \mathrm{E} 14 \mathrm{Nm}$, corresponding to a moment magnitude $\mathrm{M}_{\mathrm{w}}$ 3.5. The source mechanism from a first motion fault plane solution shows a leftlateral strike-slip mechanism with a minor dip-slip component along fault NNW striking at $161^{\circ}$, dipping $52^{\circ}$ to the west and rake $-5^{\circ}$.

The RSTFs are relatively complex pulse with maximum amplitude at GLL station (Figure 5) at azimuth $15^{\circ}$. The shape and amplitude of the RSTFs reflect a rupture direction in NEE-SWW trend.

\section{$5 \quad$ Source Parameters Estimations}

Source parameters, especially stress drop are crucial in microzonation and the assessment of seismic hazard. The static stress drop is calculated from seismic moment and fault radius. The seismic moment for the EGF was calculated based on the low-frequency amplitudes spectrum $\left(\Omega_{\mathrm{o}}\right)$ using the following relationship (Brune, 1970, 1971)

$$
M_{o}=\Omega_{o} \frac{4 \pi \rho v^{3} d}{R(\theta, \varphi)}
$$


where $\rho$ is the density, $d$ is the hypocentral distance and $R$ (q,f) is the radiation pattern coefficient. The seismic moment of the master event $M m$ are estimated by $M m=A M$ o where $A$ is the average area under the RMRF's.

The rise times were measured from RMRF's at the nearest four stations to estimate the fault radius using the relationship given by Boawright (1980) for a circular source.

$$
r=\frac{\tau_{1 / 2} v_{r}}{1-\left(\frac{v_{r}}{c} \sin \theta\right)}
$$

where $\boldsymbol{c}$ and $\boldsymbol{V}$ are the velocities of the P- wave and rupture, respectively, and $\mathrm{q}$ is the take-off angle. The p- wave velocity is $6.5 \mathrm{~km} / \mathrm{sec}$, the rupture velocity is assumed to be 0.9 times the shear wave velocity, and $45^{\circ}$ for $\square$. The static stress drop is determined from the seismic moment and fault radius using Brune's $(1970,1971)$ formula:

$$
\Delta \sigma=0.44 \frac{M_{o}}{r^{3}}
$$

The calculated source parameters (seismic moment, fault radius, and stress drop) are summarized in Table 1. We have compared our estimates of source parameters with those obtained by spectral technique for the master earthquakes (Badawy and Abdel Fattah, 2002; Badawy et al., 2008). These results are greatly conformable with the source parameters that estimated using EGF.

\section{Discussion and Conclusions}

We have adapted the empirical Green function strategy as a linear inversion problem by using a small aftershock for removing complicated path, site and instrument effects. This process provides isolated moment rate function with a high frequency resolution. The relative source time functions (RSTFs) which resulted from the inversion are used to retrieve the source characterization of five small felt inland earthquakes in northern Egypt. The detailed analysis of source process led us to interpret these events as complex sources separated in space and time for strike-slip (events no1 and 5 Table 1). The monitoring of mainshock waveforms shows evidence for a variation in focal mechanism during the rupture. This is well illustrated by the change in polarity between the first motion and successive subevents at station AYT in figure 3. The location of late sub-events to initiation point of the southeast Beni-Suef earthquake rupture suggested that the mainshock rupture propagated predominately toward the north. The relative sub-event location is conformable to the NNW-SSE striking which determined from focal mechanism solution. The rupture direction in conjunction with the focal mechanism solution can be used to determine which nodal plane is the actual fault plane (Frankel et al., 1986; Li and Thurber, 1988; Mori and Frankel, 1990; Mori, 1993; Li et al., 1995; Badawy and Abdel-Fattah, 2002). Our preferred fault plane is the one that has a NNW trend, which is also confirmed by the aftershock distribution (Badawy and Abdel-Fattah, 2000). Based on geological and seismicity information, investigators can sometimes determine the actual fault plane for an earthquake, but for most events, choosing the nodal plane that represents the actual fault plane is difficult. However, this study and previous investigations have shown that the combination of rupture directivity and focal mechanism is suitable for earthquake pairs and is possible to determine the actual fault planes for the larger events in the pairs.

The source parameters estimated from the derived RSTF's vary from $1.76 \mathrm{E} 14$ to $5.55 \mathrm{E} 15 \mathrm{~N}-\mathrm{m}$ for seismic moment, from 23.8 to $49.1 \mathrm{MPa}$ for stress drop and from 500 to $1500 \mathrm{~m}$ for fault radius. These parameters agree well with values that obtained by spectra analysis technique (Badawy and AbdelFattah, 2002) for the southeast Beni-Suef earthquake and also for earthquakes in northern Egypt (Badawy, 1995; Badawy and Mónus 1995; Badawy and Abdel-Fattah, 2002). Finally, the analysis of the respective events revealed complex rupture for strike-slip events and the large estimated stress drop for the main rupture resembled the failure asperity. However, the dip-slip earthquakes possess a simple rupture mechanism. The shape and durations of the source time functions of thrust and normal earthquakes appear to be somewhat different from that of the strike-slip events (Houston, 2001). It is possible that the strike-slip events are likely to rupture bilateral than dip-slip earthquakes. 


\section{References}

1. A. K. Abdel-Fattah. Source characteristics of the 28th January 1999 Nagano earthquake, Japan. IISEE, Vol.35: 45-57, 1999.

2. K. M. Abou Elenean Focal mechanisms of small and moderate size earthquakes recorded by the Egyptian National Seismic Network (ENSN), Egypt, NRIAG. J Geophys 6(1):119-153, 2007.

3. K. Aki,: Scaling law of seismic spectrum, J. Geophys. Res., vol. 72, p. 1217-1231, 1967.

4. C. J. Ammon,,: A comparison of deconvolution techniques, Lawrence Livermore National Laboratory Report, UCID-ID-111667, p. 1-43, 1992 .

5. C. L. Ammon, , A. A. Velasco, and T. Lay,: Rapid estimation of rupture directivity: Application to the 1992 Landers $(\mathrm{Ms}=7.4)$ and Cape Mendocino $(\mathrm{Ms}=7.2)$ California Earthquakes, Geophys. Res. Lett., vol. 20, p. 97100, 1993 .

6. A. Badawy: Source parameters and tectonic implications of recent Sinai (Egypt) earthquakes. Acta Geod. Geoph. Hung., 30: 349-361, 1995.

7. A. Badawy, Seismicity and kinematic evolution of the Sinai plate. Ph D thesis, pp115, L. Eötvös Univ. Budapest, 1996.

8. A. Badawy: Historical seismicity of Egypt. Acta Geod. Geoph. Hung., 34 (1-2): 119- 135, 1999.

9. A. Badawy: Status of the crustal stress as inferred from earthquake focal mechanisms and borehole breakout in Egypt. Tectonophysics, 343 (1-2): 49-61, 2001a.

10. A. Badawy: The present-day stress field in Egypt. Annali Di Geofisica 44 (3): 557- 570, $2001 \mathrm{~b}$.

11. A. Badawy: Seismicity of Egypt. Seismolo. Res. Lett. 76 (2) 149-160, (2005a.

12. A. Badawy: Present-day seismicity, stress field and crustal deformation of Egypt. Journal of Seismology, 9 (3):267-276, 2005b.

13. A. Badawy and A. K. Abdel-Fattah: Source parameters and fault plane determinations of the 28 December, 1999 northeastern Cairo earthquakes. Tectonophysics, 343:63-77, 2001.

14. A. Badawy and A. K. Abdel-Fattah: Analysis of the southeast Beni-Suef, northern Egypt Earthquake sequence. J. Geodynamics. 33 (3): 219-234, 2002.

15. A. Badawy and P. Mónus : Dynamic source parameters of the 12th October, 1992 earthquake, Cairo, Egypt. J. Geodynamics, 20: 99-109, 1995.

16. A. Badawy and F. Horváth: Seismicity of the Sinai subplate region: Kinematic implications. J. Geodynamics, 27 : 451-468, 1999a .

17. A. Badawy and F. Horváth: Sinai subplate and kinematic evolution of the northern Red Sea. J. Geodynamics, 27: 433-450, 1999b.

18. A. Badawy, S. M. Abdel-Monem, K. Sakr, and N. Abo-Ali,: Seismicity and kinematic evolution of the middle Egypt. J. Geodynamics 42: 28-37, 2006.

19. A. Badawy, A. K. Abdel-Fattah, Sh. M. Ali, and W. Farid,: Source parameters of the ML 4.1 earthquake of November 08, 2006, southeast Beni-Suef, northern Egypt, Journal of African Earth Sciences, vol. 51, p. 151-159, 2008.

20. A. Badawy, A., Al-werr, and Sh. M. Ali., Relative location and source mechanism of inland earthquakes in northern Egypt. J. Seismology Doi10.1007/s10950-01-13-9387-z, 2014 .

21. M. Bertero, D. Bindi, P. Boccacci, M. Cattaneo, C. Eva, and V. Lanza,: Application of the projected Landweber method to the estimation of the source time function in seismology, Inverse Problems, vol.13, p. 465-486, 1997.

22. J. Boatwright: A spectral theory for circular seismic sources: simple estimates of source dimension, dynamic stress drop and radiated energy. Bull. Seism. Soc. Am., 70: 1-28, 1980.

23. J. Brune, : Tectonic stress and the spectra of seismic shear waves from earthquakes. J. Geophys. Res., 75: 4997$5009,1970$.

24. J. Brune,: Correction. J. Geophys. Res., 76: 5002, 1971.

25. F. Courboulex, J. Virieux, A. Deschamps, D. Gibert, and A. Zollo, : Source investigation of a small event using empirical Green's functions and simulated annealing, Geophys. J. Int., vol. 125, p. 768-780, 1996.

26. M. DiBona, and J. Boatwright: Single-station decomposition of seismograms for subevent time history. Geophy. J. Inter., 105: 103-117, 1989. 
27. W. L. Ellsworth, and G. C. Beroza: Seismic evidence for an earthquake nucleation phase. Science, 268: 851-855, 1995.

28. A. Frankel, J. Fletcher, F. Vernon; L. Haar; J. Berge; T. Hanks and J. Brune: Rupture characteristics and tomographic imaging of $\mathrm{ML}=3$ earthquakes near Azna southern California, J. Geophys. Res., 91: 12633-12650, 1986.

29. E. Fukuyama and K. Irikura, : Rupture process of the 1983 Japan Sea (Akita-Oki) earthquake using a waveform inversion method, Bull. Seism. Soc. Am., vol. 76, p. 1623-1640, 1986.

30. D. M. Hadley, and D. V. Helmberger : Simulation of strong ground motion. Bull. Seism. Soc. Am., 70: 617-630, 1980.

31. S. H. Hartzell,: Earthquake aftershocks as Green's functions. Geophys. Res Lett., 5: 1- 4, 1978.

32. S. H. Hartzell and T. H. Heaton: Teleseismic time functions for large, shallow subduction zone earthquakes, Bull. Seism. Soc. Am., vol. 75, p. 965-1004, 1985 .

33. H. Houston: Influence of depth, focal mechanism and tectonic setting on the shape and duration of earthquake source time functions. J. Geophys. Res., 106:11137-11150, 2001.

34. P. F. Ihmle: Frequency dependent relocation of the 1992 Nicaragua slow earthquake: an empirical Green's function approach, Geophys. J. Int., vol.127, p. 75-85, 1996.

35. K. Irikura, and I. Muramatu: Synthesis of strong ground motions during large earthquakes. Bull. Disaster. Prev. Res. Inst., Kyoto Univ., 33: 63-104, 1982.

36. H. Kanamori,. A semi-empirical approach to prediction of long-period ground motions from great earthquakes. Bull. Seism. Soc. Am., 69: 1645-1670, 1979.

37. C. L. Lawson, and R. J. Hanson:. Solving Least Squares Problems, Prentics-Hall, Inc., New Jersey. 1974.

38. Y. Li, and C. H. Thurber: Source properties of two microearthquakes in Kilauea volcano, Hawaii, Bull. Seism. Soc. Am., 78: 1123-1132, 1988 .

39. Y. Li, C. Doll and M. N. Toksoz: Source characterization and fault plane determination for M $b L g=1.2$ to 4.4 earthquakes in the Charlevoix Seismic Zone, Quebec, Canada. Bull. Seism. Soc. Am., 85: 1604-1621, 1995.

40. J. Mori, Fault plane determinations for three small earthquakes along San Jacinto fault California: search for cross faults. J. Geophy. Res., 98: 17711-17722, 1993.

41. J. Mori and A. Frankel : Source parameters for small events associated with the 1986 North Palm Springs, California, earthquake determined using empirical Green's functions. Bull. Seism. Soc. Am., 80: 278-295, 1990.

42. C. Mueller: Source pulse enhancement by deconvlution of an empirical Green's function. Geophys. Res. Lett., 12: 33-36, 1985.

43. R. Said, : The geology of Egypt. Elsevier, Amsterdam, the Netherlands, 1962.

44. J. C. Savage and H. S. Hasegawa: Some properties of tensile inferred from elastic wave radiation. J. Geophys. Res., 69: 2091-2106, 1964.

45. N. Shukri: The geology of the desert east of Cairo, Bull. Inst. Desert, Egypt, 3(2): 89-105, 1952.

46. S. A. Sipkin, and A. L. Lerner-Lam: Pulse-shape distortion introduced by broadband deconvolution, Bull. Seism. Soc. Am., vol. 82, p. 238-258, 1992.

47. M. Valle: Stabilizing the empirical Green function analysis: development of the projected Landweber method, Bull. Seism. Soc. Am., vol. 94, p. 394-409, 2004.

48. A. A. Velasco, C. J. Ammon, and T. Lay,: Empirical Green function deconvolution of broadband surface waves: rupture directivity of the 1992 Landers, California (Mw_7.3), Bull. Seism. Soc. Am., vol. 84, p. 735-750, 1994.

49. F. Wu and H. Kanamori: Source mechanism of the February 4, 1965 Rate Island earthquake. J. Geophys. Res., 78: 6082-6092, 1973.

50. J. Xie, Z. Liu; R. Herrmann and E. Cranswick: Source processes of three aftershocks of the 1983 Goodnow, New York, earthquake: high resolution images of small symmetric rupture. Bull. Seism. Soc. Am., 81: 818-843, 1991. 